This item was submitted to Loughborough's Research Repository by the author.

Items in Figshare are protected by copyright, with all rights reserved, unless otherwise indicated.

\title{
Comparison of two- and three-dimensional methods for analysis of trunk kinematic variables in the golf swing
}

\section{PLEASE CITE THE PUBLISHED VERSION}

http://dx.doi.org/10.1123/jab.2015-0032

\section{PUBLISHER}

(c) Human Kinetics

\section{VERSION}

AM (Accepted Manuscript)

\section{PUBLISHER STATEMENT}

This work is made available according to the conditions of the Creative Commons Attribution-NonCommercialNoDerivatives 4.0 International (CC BY-NC-ND 4.0) licence. Full details of this licence are available at: https://creativecommons.org/licenses/by-nc-nd/4.0/

\section{LICENCE}

CC BY-NC-ND 4.0

\section{REPOSITORY RECORD}

Mears, Aimee, Jonathan Roberts, Eric S. Wallace, Pui W. Kong, and Steph Forrester. 2019. "Comparison of Two- and Three-dimensional Methods for Analysis of Trunk Kinematic Variables in the Golf Swing". figshare. https://hdl.handle.net/2134/21663. 


\title{
Comparison of two- and three-dimensional methods for analysis of trunk kinematic variables in the golf swing
}

\author{
Aimée C. Smith ${ }^{1,2}$, Jonathan R. Roberts ${ }^{1}$, Eric S. Wallace ${ }^{3}$, Pui Wah Kong ${ }^{4}$, Stephanie E. Forrester ${ }^{1}$ \\ 1. Wolfson School of Mechanical and Manufacturing Engineering, Loughborough University, Loughborough, UK. \\ 2. Institute for Sports Research, Nanyang Technological University, Singapore \\ 3. Sport and Exercise Sciences Research Institute, University of Ulster, Newtonabbey, Northern Ireland. \\ 4. Physical Education and Sports Science Academic Group, National Institute of Education, Nanyang Technological \\ University, Singapore
}

KEYWORDS golf, three-dimensional, two-dimensional, X-factor, trunk kinematic variables

\begin{abstract}
Two-dimensional methods have been used to compute trunk kinematic variables (flexion/extension, lateral bend, axial rotation) and X-factor (difference in axial rotation between trunk and pelvis) during the golf swing. Recent Xfactor studies advocated three-dimensional $(3 \mathrm{D})$ analysis due to the errors associated with two-dimensional $(2 \mathrm{D})$ methods, but this has not been investigated for all trunk kinematic variables. The purpose of this study was to compare trunk kinematic variables and X-factor calculated by $2 \mathrm{D}$ and ${ }_{3} \mathrm{D}$ methods to examine how different approaches influenced their profiles during the swing. Trunk kinematic variables and X-factor were calculated for golfers from vectors projected onto the global laboratory planes and from $3 \mathrm{D}$ segment angles. Trunk kinematic variable profiles were similar in shape; however, there were statistically significant differences in trunk flexion $(-6.5 \pm 3.60)$ at top of backswing and trunk right-side lateral bend $\left(8.7 \pm 2.9^{\circ}\right)$ at impact. Differences between $2 \mathrm{D}$ and ${ }_{3} \mathrm{D}$ X-factor (approximately $16^{\circ}$ ) could largely be explained by projection errors introduced to the $2 \mathrm{D}$ analysis through flexion and lateral bend of the trunk and pelvis segments. The results support the need to use a $3 \mathrm{D}$ method for kinematic data calculation in order to accurately analyse the golf swing
\end{abstract}

\section{Introduction}

The methods used to compute golfer kinematics during the golf swing have recently received increased attention in the biomechanics literature. ${ }^{1-3}$ In particular, the suitability of using two-dimensional (2D) methods for computing golfer kinematics, specifically X-factor (defined as the relative axial rotation of the trunk and pelvis segments), has been questioned, and three-dimensional (3D) methods have been proposed to better represent the varying orientation (ie, flexion/extension, lateral bend, and axial rotation) of the trunk and pelvis throughout the golf swing ${ }^{2,3}$

In the golf biomechanics literature, trunk flexion and lateral bend have typically been reported as $2 \mathrm{D}$ angles ${ }^{\cdot 4,5}$ For right-handed golfers, 2D trunk flexion and trunk right-side lateral bend have been found to be important predictors of driving ball velocity. ${ }^{5} \mathrm{~A}$ minimal change in golfers' $2 \mathrm{D}$ trunk flexion from top of the backswing to impact has been described as beneficial for allowing body and club rotations to remain on a plane. ${ }^{5}$ Twodimensional trunk right-side lateral bend increased from 40 milliseconds before impact to the time of impact, which the authors described as upper body lag. ${ }^{5}$ However, McTeigue et $\mathrm{al}^{6}$ acknowledged the oversimplification of $2 \mathrm{D}$ interpretation of trunk flexion and suggested that maintaining constant lower trunk flexion could cause excessive movement in other directions (ie, lateral bend angles). Two-dimensional and $3 \mathrm{D}$ trunk flexion, lateral bend, and rotation angles have not been compared during the golf swing and could suffer from similar limitations to the recently critiqued X-factor computations.

Trunk axial rotation is a contributor to the much studied X-factor. ${ }^{7} \mathrm{X}$-factor has been found to correlate with performance measures such as ball velocity ${ }^{5,8}$ and clubhead linear velocity at impact ${ }^{9}$. Previous 2D approaches for computing $\mathrm{X}$-factor have defined the angle between vectors representing the trunk and pelvis segments when projected onto the global horizontal plane $e^{8,10}$ or functional swing plane. ${ }^{3}$ In situations where these vectors do rotate in a plane parallel to the horizontal plane, then this simplification would be unlikely to introduce a significant error in X-factor values. However, in reality, the golfer's trunk and pelvis rotate about an inclined axis ${ }^{5,6}$ and with 6 degrees of freedom; thus, projecting the trunk and pelvis vectors onto the global horizontal plane 
will introduce errors to the $2 \mathrm{D} \mathrm{X}$-factor calculation. Even projecting onto the functional swing plane, defined from the clubhead trajectory in the downswing, ${ }^{3}$ has limitations as this plane has been shown to vary throughout the downswing. ${ }^{12}$

Due to these limitations, $3 \mathrm{D} \mathrm{X}$-factor is suggested to provide a more accurate estimate of the difference in axial rotation between the golfer's trunk and pelvis during the golf swing. ${ }^{1-3,13}$ Both Brown et al2 and Kwon et $\mathrm{al}^{3}$ compared the $2 \mathrm{D}$ projection methods (horizontal and swing plane projections) and relative $3 \mathrm{D}$ axial rotation of the trunk and pelvis for calculating X-factor. Larger X-factor was computed using the $2 \mathrm{D}$ projection method compared with $3 \mathrm{D}$ methods throughout the downswing and was attributed in part to the changing pelvis and trunk orientations (ie, flexion/extension, lateral bend, axial rotation) of individual golfers. ${ }^{3}$ Nevertheless, neither study quantified the contribution of changing pelvis and trunk orientations to the difference in $2 \mathrm{D}$ and ${ }_{3} \mathrm{D} \mathrm{X}$-factor or the improvement in accuracy gained by $3 \mathrm{D}$ analysis and thus it is unknown whether the additional complexity of a $3 \mathrm{D}$ analysis is necessary.

The purpose of this study was to compare trunk flexion, trunk lateral bend, trunk axial rotation, and X-factor calculated using $2 \mathrm{D}$ and $3 \mathrm{D}$ methods, in the general golfing population, to address 2 research questions. The first research question posed was how different are $2 \mathrm{D}$ and $3 \mathrm{D}$ trunk kinematic variables (flexion/extension, lateral bend, and axial rotation) at key instances (takeaway, top of the backswing, and impact) and throughout the swing? It was hypothesized that $2 \mathrm{D}$ trunk kinematic variables would be significantly greater than $3 \mathrm{D}$ trunk kinematic variables, in particular at top of the backswing and impact, as previous literature had shown for trunk axial rotation. ${ }^{3,14}$

The second research question posed was to what extent does a golfer's trunk and/or pelvis orientation, relative to the global coordinate system, account for the differences between $2 \mathrm{D}$ and $3 \mathrm{D}$ analyses of X-factor? Based on previous studies, ${ }^{2,3}$ it was hypothesized that trunk and pelvis orientations would be significant predictors of the difference between $2 \mathrm{D}$ and $3 \mathrm{D} \mathrm{X}$-factor. The comparison between $2 \mathrm{D}$ and $3 \mathrm{D}$ methods may help interpretation of results from biomechanics literature regarding trunk kinematics and provide further evidence on whether a ${ }_{3} \mathrm{D}$ analysis of the golfer kinematics during the golf swing is necessary.

\section{Methods}

\section{Participants}

Whole body kinematics were recorded for fifteen righthanded golfers (age $30 \pm 10$ years, mass $77.0 \pm 11.9 \mathrm{~kg}$, height $1.77 \pm 0.07 \mathrm{~m}$ ) of varying abilities (handicap range 1 - 29). All subjects gave their informed consent and ethical clearance was obtained from the University Ethical Advisory Committee.

\section{Data collection}

Fifty-five $14 \mathrm{~mm}$ diameter reflective markers were placed on the golfer at anatomical positions and five markers, including one wand marker, were placed on the golfer's own driver (Figure 1). A piece of reflective tape was placed on the golf ball enabling the instant of impact to be determined. Three-dimensional marker trajectories were collected using a thirteen camera Vicon Nexus Motion Analysis System (Oxford Metrics Ltd, UK) sampling at $250 \mathrm{~Hz}$. The Vicon Nexus motion analysis system used in this study was capable of repeatedly measuring known distances and angles within $0.2 \mathrm{~mm}$ and less than $0.2^{\circ}$ respectively throughout the capture volume which were measured using methods similar to Richards ${ }^{15}$.
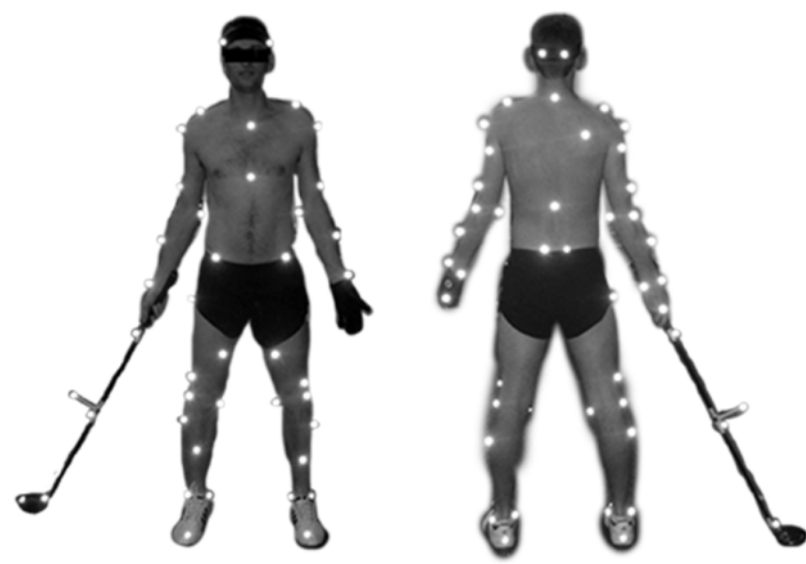

Figure 1. Marker set-up including seventh cervical vertebrae $\left(C_{7}\right)$, tenth thoracic vertebrae (T1o), clavicle and sternum right and left; front and back head, acromion processes (RAC, LAC), shoulder (RSHO, LSHO), upper arm (three markers each), lateral and medial elbow epicondyles, forearm, medial and lateral wrist, hand, anterior and posterior superior iliac spine (RASI, LASI, RPSI, LPSI), thigh (three markers each), lateral and medial femoral epicondyle, shank (two markers each), lateral and medial malleoli, first metatarsal. Club markers include markers on the grip, shaft, heel and toe and a wand marker on the shaft.

Golfers wore their own golf shoes and glove, used the same brand golf ball (Titleist ProV1) throughout and hit from an artificial golf range mat into an indoor net positioned approximately four meters away; a vertical pole positioned behind the net provided a target line. The global co-ordinate system (GCS) origin $(0,0,0)$ was at ground level in the middle of the capture volume. The positive GCS axes were defined from the origin, with the $\mathrm{X}$-axis directed parallel to the target line but away from the target, the Y-axis directed anteriorly to the golfer and the Z-axis was directed vertically upwards.

Each golfer performed a warm up at their own discretion before testing began. The golfer then performed ten shots with their driver, with adequate rest between, based on the instruction to address the ball in their normal stance position and to hit a full shot aimed towards the target line. Following each shot, the golfer gave a subjective assessment of shot quality on a 10-point scale (1-10) where the highest rating was considered representative of their best shot. 


\section{Data analysis}

Marker positions were labelled using Vicon Nexus (Oxford Metrics Ltd, UK) and further processing was done using Visual3D (C-Motion, USA). Marker trajectories were filtered using a fourth order zero-lag Butterworth low-pass filter with a cut-off frequency of $15 \mathrm{~Hz}$. Five trials per golfer were selected for analysis based on the quality of data and a high subjective rating of shot quality, similar to the criteria proposed by Wheat et al. ${ }^{13}$.

The methods used to calculate the variables trunk flexion, trunk lateral bend, trunk axial rotation and X-factor (trunk and pelvis) are summarized in Table 1 . The $2 \mathrm{D}$ method involved projecting trunk and pelvis vectors onto the global sagittal plane (flexion), frontal plane (lateral bend) and horizontal plane (rotation and X-factor). For the $3 \mathrm{D}$ method a Cardan rotation order of YXZ was selected to give the most appropriate representation of trunk flexion, lateral bend and axial rotation throughout the golf swing as also noted by Joyce et al.. ${ }^{1}$ Notably, all the methods were based on the same trials and marker positional data, but only differed in whether trunk kinematic variables or $\mathrm{X}$-factor was determined from $3 \mathrm{D}$ segment angles or from their $2 \mathrm{D}$ projections onto the global planes. For $2 \mathrm{D}$ and $3 \mathrm{D}$ angles, positive angles represented trunk extension, trunk right-side lateral bend and axial rotation towards the target.

All kinematic data were cropped from takeaway to the mid follow-through, with top of the backswing and impact also identified. These key instances were defined using the following threshold functions: takeaway when the $\mathrm{x}$-component of velocity of the clubhead heel marker first increased above $0.2 \mathrm{~ms}-1$; top of the backswing when the $\mathrm{x}$-component of velocity of the clubhead heel marker changed from negative to positive; impact as the frame where ball $\mathrm{x}$-position first changed; and mid follow-through when the club shaft was parallel to the global $\mathrm{x}$-axis following impact. The five cropped swings for each golfer were then time normalized in MATLAB (The Mathworks, Natick, MA) using the piecewise linear length normalization technique to align data from takeaway to top of the backswing, top of the backswing to impact, and impact to mid follow-through ${ }^{16}$. Ensemble averages for the entire group were calculated from the individual golfer averages.

\section{Statistical Analysis}

Statistical analysis was completed in MATLAB and SPSS v14 (IBM Inc., Armonk, NY). Mean difference, standard deviation of the difference, and 95\% limits of agreement (LoA) were calculated for values at takeaway, top of the backswing, and impact for trunk extension, trunk right-side lateral bend, and trunk axial rotation to assess agreement between $2 \mathrm{D}$ and $3 \mathrm{D}$ methods. A positive mean difference signified greater trunk extension, greater rightside lateral bend, and greater trunk axial rotation when computed using $2 \mathrm{D}$ methods compared with $3 \mathrm{D}$ methods. A two-way repeated-measures ANOVA $(2 \times 3)$ was performed on each of the 3 dependent variables (trunk extension, trunk right-side lateral bend, and trunk axial rotation) between 2 methods $(2 \mathrm{D}$ and $3 \mathrm{D})$ and 3 swing instances (takeaway, top of the backswing, impact). If there was a significant interaction between method and swing instance, the effect of the method was analyzed for each swing instance using a one-way ANOVA. Normality and sphericity were checked and confirmed for all dependent variables and the significance level was set at $\mathrm{P}<$ .05. Ensemble average curves and mean difference curves of all trunk angles were visually analyzed for deviations between $2 \mathrm{D}$ and $3 \mathrm{D}$ methods.

To approximate the contributions of pelvis and trunk orientation to the difference in X-factor at top of the backswing calculated using $2 \mathrm{D}$ and $3 \mathrm{D}$ methods, a mixedeffects linear regression model was fitted to the difference between $2 \mathrm{D}$ and $3 \mathrm{D} \mathrm{X}$-factor (dependent variable) and the $3 \mathrm{D}$ pelvis and trunk extension, lateral bend, and axial rotation angles (6 explanatory variables). The golfer was treated as a random effect in the mixed-effects linear regression model to account for the 5 repeated trials for each golfer. A backward elimination method was employed whereby all explanatory variables were considered in the regression model and explanatory variables that did not contribute to the overall significance of the model (ie, $\mathrm{P}<.05$ ) were removed in a stepwise manner and not considered in the adjusted $\mathrm{R}_{2}$ value. $\mathrm{X}$-factor values at top of the backswing were chosen as this was the swing instance often related to measures of performance such as ball velocity ${ }^{5}$

\section{Results}

The results from the comparison of $2 \mathrm{D}$ and ${ }_{3} \mathrm{D}$ trunk kinematic variables helped answer question one and provided evidence regarding the first hypothesis. The general shapes of $2 \mathrm{D}$ and $3 \mathrm{D}$ trunk angles were similar when considering group ensemble averages (Figure 2a, c, e). However, $2 \mathrm{D}$ methods resulted in less trunk extension and less trunk axial rotation towards the target (i.e. greater negative mean difference) from TA to TB (Figure $2 b, f$ ) which helped answer the first research question and provided evidence regarding the first hypothesis.

The mean difference between $2 \mathrm{D}$ and $3 \mathrm{D}$ methods for trunk angles across all swing instances ranged from approximately $3^{-0}$ to ${ }^{-11^{\circ}}$ (Table 2 ). The two-way repeated measures ANOVA analysis confirmed that there was a significant interaction between methods ( $2 \mathrm{D}$ vs. $3 \mathrm{D})$ and swing instances (TA, TB, IMP) for trunk extension $(F(2,28)=29.38, P<.001)$, trunk right-side lateral bend $(F(2,28)=48.22, P<.001)$ and trunk axial rotation $(\mathrm{F}(2,28)$ $=15.86, P<.001)$. Therefore, a comparison between $2 \mathrm{D}$ and ${ }_{3} \mathrm{D}$ methods at each swing instance for each trunk angle was performed. At TA there were small nonsignificant mean differences between $2 \mathrm{D}$ and $3 \mathrm{D}$ trunk angles but there were statistical differences at TB and IMP. At TB, the $2 \mathrm{D}$ trunk flexion was significantly greater compared to $3 \mathrm{D}\left(-6.54 \pm 3.64^{\circ}, P<.001\right)$. At the same instance, $2 \mathrm{D}$ trunk axial rotation away from the target was greater than $3 \mathrm{D}\left(-10.97 \pm 5.87^{\circ}\right)$ which approached significance $(P=.068)$ (Table 2$)$. The Limits of Agreement at TB were wide across all trunk angles $\left(-14\right.$ to $\left.-23^{\circ}\right)$. At IMP, $2 \mathrm{D}$ 
trunk right-side lateral bend angles was significantly less than the $3^{\mathrm{D}}$ angles $(P=.002)$. At IMP, the Limits of Agreement were again wide across trunk angles ( -4 to $\left.22^{\circ}\right)$.
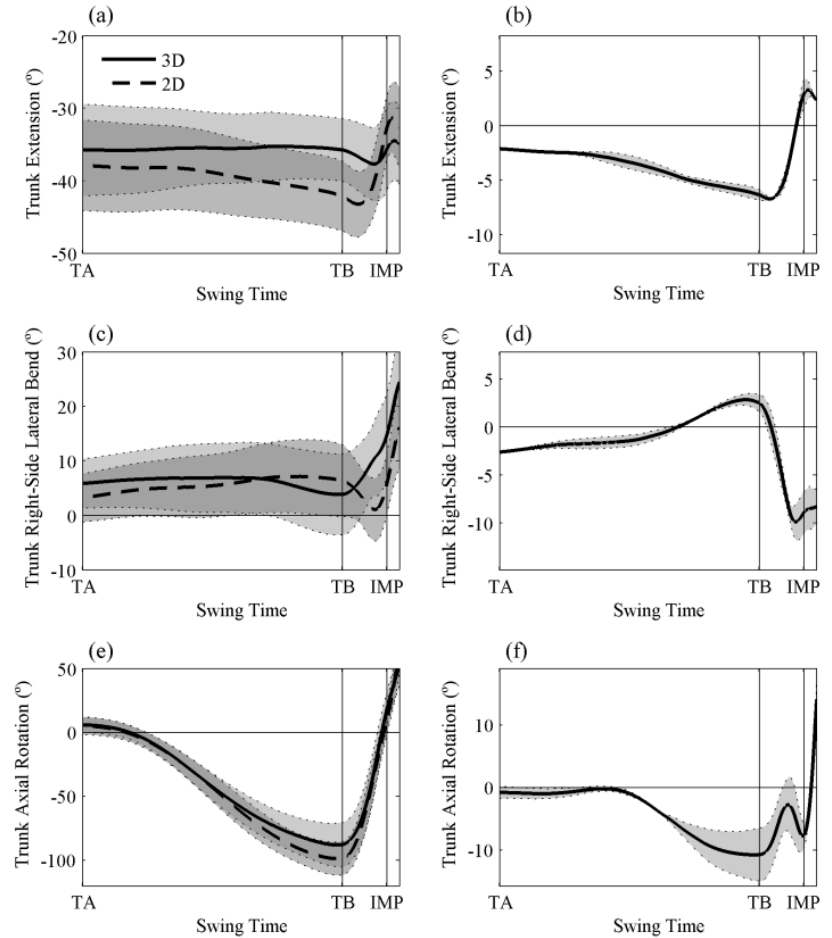

Figure $2-2 \mathrm{D}$ (dashed) and $3 \mathrm{D}$ (solid) ensemble average curves \pm one standard deviation (shaded region) for (a) trunk extension, (c) trunk right-side lateral bend and (e) trunk axial rotation for all golfers and mean difference $(2 \mathrm{D}-3 \mathrm{D})$ of (b) trunk extension, (d) trunk right-side lateral bend and (f) trunk axial rotation (towards target) for all golfers. A positive mean difference represented $2 \mathrm{D}$ methods had computed greater trunk extension, greater trunk right-side lateral bend and greater trunk axial rotation towards the target compared to $3 \mathrm{D}$ methods. $\mathrm{TA}=$ takeaway, $\mathrm{TB}=$ top of the backswing, IMP = impact.

Table 1 Summary of the methods used to calculate two- and three-dimensional trunk flexion, lateral bend, rotation and $\mathrm{X}$-factor.

\begin{tabular}{|c|c|c|c|c|c|}
\hline \multicolumn{2}{|c|}{ Parameter } & \multirow{2}{*}{$\begin{array}{l}\text { 2D Definition } \\
\text { Vector between } C_{7} \text { and } \\
\text { Mid-PSIS markers. }\end{array}$} & \multirow{2}{*}{$\begin{array}{l}\text { 2D Angle } \\
\text { Vector projected onto } \\
\text { GCS sagittal plane and } \\
\text { vector measured relative } \\
\text { to vertical Z-axis }\end{array}$} & \multirow[b]{2}{*}{$\begin{array}{l}\text { 3D Definition } \\
\text { Origin: Mid-acromion and } \\
\text { halfway to T1o } \\
\text { x-axis: } z \text {-axis to right acromi- } \\
\text { on } \\
\text { y-axis: cross product of } \mathrm{x} \text { and } \\
\text { z-axis } \\
\text { z-axis: Origin to mid acromi- } \\
\text { on }\end{array}$} & \multirow{2}{*}{$\begin{array}{l}\text { 3D Angle } \\
\text { Rotation about GCS } \\
\text { frontal horizontal } \\
\text { axis (X-axis). }\end{array}$} \\
\hline $\begin{array}{l}\text { Trunk } \\
\text { sion }\end{array}$ & Exten- & & & & \\
\hline $\begin{array}{l}\text { Trunk } \\
\text { Bend }\end{array}$ & Lateral & $\begin{array}{l}\text { Vector between } C_{7} \text { and } \\
\text { Mid-PSIS markers. }\end{array}$ & $\begin{array}{l}\text { Vector projected onto } \\
\text { GCS frontal plane and } \\
\text { vector measured relative } \\
\text { to vertical Z-axis }\end{array}$ & & $\begin{array}{l}\text { Rotation about GCS } \\
\text { sagittal horizontal } \\
\text { axis (Y-axis). }\end{array}$ \\
\hline $\begin{array}{l}\text { Trunk } \\
\text { Rotation }\end{array}$ & Axial & $\begin{array}{l}\text { Vector between right } \\
\text { and left acromion } \\
\text { markers. }\end{array}$ & $\begin{array}{l}\text { Vector projected onto } \\
\text { GCS horizontal plane } \\
\text { and vector measured } \\
\text { relative to Y-axis }\end{array}$ & & $\begin{array}{l}\text { Rotation about GCS } \\
\text { vertical axis ( } \mathrm{Z} \text {-axis). }\end{array}$ \\
\hline
\end{tabular}


Table 2 Mean difference, standard deviation of the difference (SD), 95\% Limits of Agreement (LoA) and $P$ values for mean $2 \mathrm{D}$ and $3 \mathrm{D}$ trunk flexion, lateral bend and axial rotation at takeaway (TA), top of backswing (TB) and impact (IMP). A negative mean difference signifies that $2 \mathrm{D}$ angles were greater than ${ }_{3} \mathrm{D}$ angles and vice versa.

\begin{tabular}{|c|c|c|c|c|c|c|}
\hline \multirow{3}{*}{$\begin{array}{l}\text { Key Instance } \\
\text { TA }\end{array}$} & \multirow{3}{*}{$\begin{array}{l}\text { Angle } \\
\text { Trunk Extension }\end{array}$} & \multicolumn{5}{|c|}{ 2D - 3D Trunk Angles (o) } \\
\hline & & \multirow{2}{*}{$\begin{array}{l}\text { Mean Difference } \\
-2.12\end{array}$} & \multirow{2}{*}{$\frac{S D}{3.01}$} & \multicolumn{2}{|c|}{$95 \%$ LoA } & \multirow{2}{*}{$\frac{P}{.370}$} \\
\hline & & & & 3.78 & -8.03 & \\
\hline TB & & -6.54 & 3.64 & 0.59 & -13.67 & $.001^{* *}$ \\
\hline IMP & & 3.03 & $3 \cdot 57$ & 10.03 & -3.98 & .117 \\
\hline $\mathrm{TA}$ & Trunk Right-side Lateral Bend & -2.61 & 2.67 & 2.62 & -7.85 & .122 \\
\hline ТВ & & 2.45 & 2.99 & 8.31 & -3.41 & .354 \\
\hline IMP & & -8.65 & 2.91 & -2.95 & -14.36 & $.002^{* *}$ \\
\hline TA & Trunk Axial Rotation & -0.77 & 5.33 & 9.69 & -11.22 & .750 \\
\hline ТВ & & -10.97 & 5.89 & 0.57 & -22.52 & .068 \\
\hline IMP & & -7.27 & $7 \cdot 37$ & 7.17 & -21.72 & .138 \\
\hline
\end{tabular}

Table 3 Mean \pm SD angles at TB of predictor variables and standardised beta coefficients ( $\beta$-coefficient), standard error (SE) and $P$ values from the stepwise mixed effects regression model.

\begin{tabular}{lllll}
\hline Variable & Mean \pm SD (o) & $\beta$-coefficient & SE & $P$ \\
\hline Pelvis Extension & $-18.26 \pm 5.85$ & 0.19 & 0.12 & .109 \\
Trunk Extension & $-35.61 \pm 4.69$ & 0.06 & 0.08 & .479 \\
Pelvis Right-side Lateral Bend & $-4.59 \pm 5.26$ & 0.20 & 0.10 & $.053^{*}$ \\
Trunk Right-side Lateral Bend & $3.86 \pm 7.48$ & -0.53 & 0.10 & $.001^{* *}$ \\
Pelvis Axial Rotation & $-44.82 \pm 10.94$ & 0.41 & 0.13 & $.003^{* *}$ \\
Trunk Axial Rotation & $-87.10 \pm 17.78$ & -1.06 & 0.13 & $.001^{* *}$ \\
\hline
\end{tabular}

${ }^{* *} P<.01,{ }^{*}$ borderline $P<.05$

When comparing trunk angles for individual golfers, greater differences were observed in the patterns between $2 \mathrm{D}$ and ${ }_{3} \mathrm{D}$ curves. To illustrate these differences, two golfers with the greatest (Golfer One, handicap $=9$ ) and least (Golfer Two, handicap $=2$ ) difference in $2 \mathrm{D}-{ }_{3} \mathrm{D}$ trunk axial rotation at TB were used as examples (Figure 3). Golfer One exhibited a greater change in $3 \mathrm{D}$ trunk extension throughout the swing with the golfer becoming more flexed towards TB compared to TA (Figure 3a). Two-dimensional trunk extension follows a similar pattern to the ${ }_{3} \mathrm{D}$ pattern but appeared to report a greater amount of trunk flexion compared to $3 \mathrm{D}$ angles (Figure 3a). The greater difference in magnitude between $2 \mathrm{D}$ and $3 \mathrm{D}$ trunk axial rotation curves, from TA to TB, can also be observed for Golfer One (Figure ze). For Golfer Two, 2D trunk flexion increases towards TB, whilst $3 \mathrm{D}$ trunk flexion remained relatively stable (Figure $3 \mathrm{~b}$ ). For the same golfer, in the late backswing, 3D trunk right-side lateral bend increased before $\mathrm{TB}$ and continued to rapidly increase during the downswing (TB - IMP) which may be seen as increased trunk flexion when reporting $2 \mathrm{D}$ angles (Figure $3 \mathrm{~d}$ ). Nevertheless, the $2 \mathrm{D}$ and $3 \mathrm{D}$ trunk rotation curves remained similar in pattern and magnitudes (Figure $3 f)$.
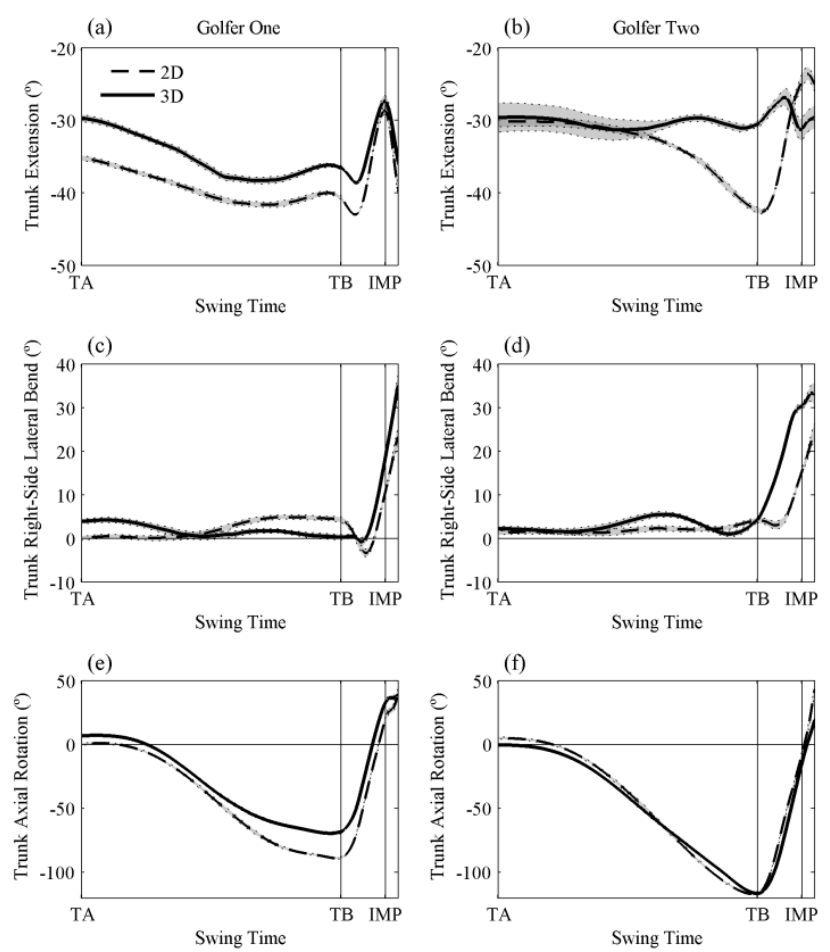

Figure 3 - Individual golfer mean curves \pm one SD (shaded region) of $2 \mathrm{D}$ (dash) and $3 \mathrm{D}$ (solid) trunk kinematics for $(\mathrm{a}, \mathrm{c}, \mathrm{e})$ Golfer One (greatest difference in axial rotation at TB) and $(\mathrm{b}, \mathrm{d}, \mathrm{f})$ Golfer Two (smallest difference in axial rotation at $\mathrm{TB})$. 

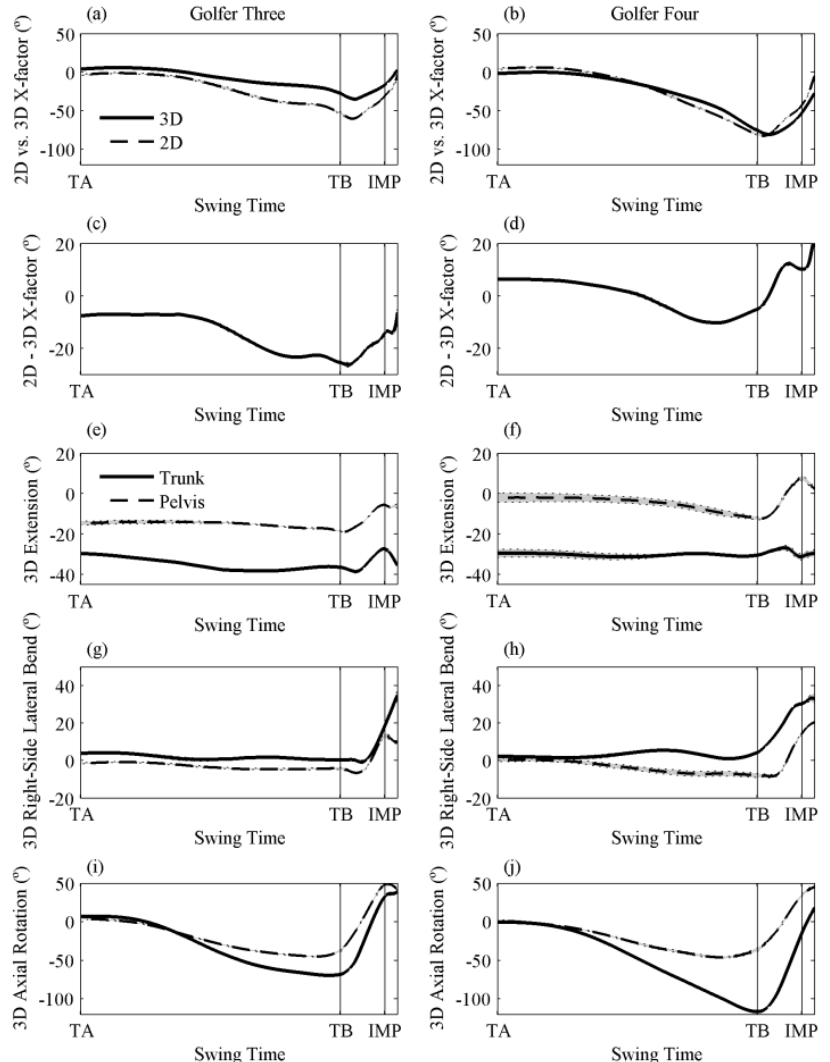

Figure 4 - Mean \pm standard deviation (solid line and shaded region respectively) of (a,b) $2 \mathrm{D}$ vs. $3 \mathrm{D} \mathrm{X}$-factor, (c,d) X-factor mean difference $(2 \mathrm{D}-3 \mathrm{D}),(\mathrm{e}, \mathrm{f}) 3 \mathrm{D}$ pelvis and trunk extension, $(\mathrm{g}, \mathrm{h}){ }_{3} \mathrm{D}$ pelvis and trunk lateral bend $(\mathrm{i}, \mathrm{j}){ }_{3} \mathrm{D}$ pelvis and trunk axial rotation for Golfer Three and Four (greatest and least difference between $2 \mathrm{D}$ and ${ }_{3} \mathrm{D} \mathrm{X}$-factor at $\mathrm{TB}$ respectively). A positive mean difference represented $2 \mathrm{D}$ methods computed greater trunk extension, greater trunk right-side lateral bend and greater trunk axial rotation towards the target compared to $3 \mathrm{D}$ methods.

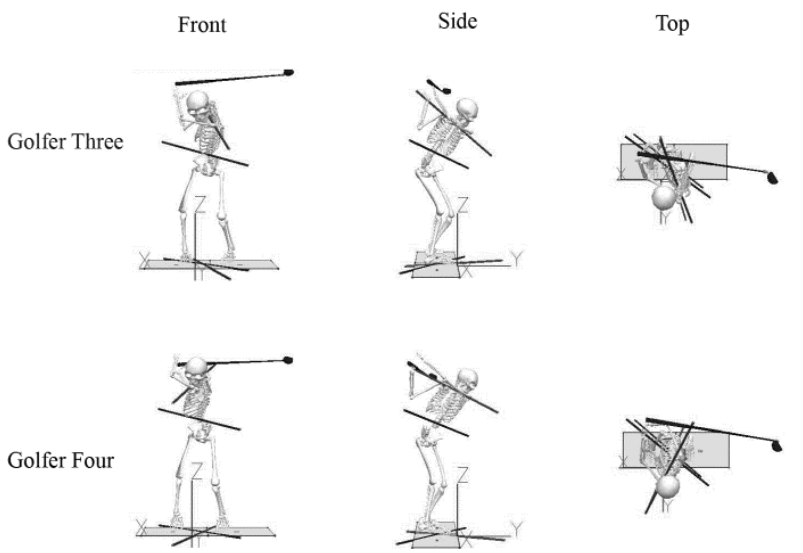

Figure 5 - Front, side and top view of golfer models with pelvis (black) and trunk (grey) vectors with projection onto the GCS horizontal plane at TB for Golfer Three and Golfer Four
From the regression analysis, of the six predictor variables, three (trunk right-side lateral bend, pelvis and trunk axial rotation) were significant and contributed to the adjusted $R^{2}$ value of 0.967 (Table 3 ). Across all golfers, the mean difference and standard deviation between $2 \mathrm{D}-3 \mathrm{D}$ $\mathrm{X}$-factor at top of the backswing was $-16.72 \pm 6.20^{\circ}$. Of these explanatory variables, the most important predictor of the difference between $2 \mathrm{D}-3 \mathrm{D} \mathrm{X}$-factor was trunk axial rotation $(\beta=-1.06)$ followed by trunk right-side lateral bend $(\beta=-0.53)$ and pelvis axial rotation $(\beta=0.41)$. The negative $\beta$-coefficients for trunk axial rotation and trunk right-side lateral bend indicated that as these variables increased by one standard deviation (i.e. less rotation away from target and greater trunk right-side lateral bend) the difference between $2 \mathrm{D}-3_{\mathrm{D}} \mathrm{X}$-factor at $\mathrm{TB}$ would increase by approximately $6.6^{\circ}$ and $3.3^{\circ}$ respectively. An increase of one standard deviation in pelvis axial rotation would reduce the difference in $2 \mathrm{D}-3 \mathrm{D} \mathrm{X}$-factor at TB (approximately $2.5^{\circ}$ ).

To further explore the results of the regression analysis two individual golfers, one with the greatest difference in $2 \mathrm{D}-3 \mathrm{D} X$-factor at TB (Golfer Three, handicap $=9$, difference $\sim-25^{\circ}$ ) and one with the smallest difference in $2 \mathrm{D}$ $-3 \mathrm{D}$ X-factor at TB (Golfer Four, handicap $=2$, difference $\sim-5^{\circ}$ ) were selected (Figure 4 and Figure 5). In terms of the significant predictor variables that emerged from the regression analysis, the major difference between golfers was in trunk axial rotation where Golfer Three had markedly less trunk axial rotation away from the target line compared to Golfer Four $\left(70^{\circ}\right.$ versus $110^{\circ}$ at TB; Figures $4 \mathrm{i}^{-}$ $\mathrm{j}$ and 5 ). In comparison, trunk right-side lateral bend (Figures $4 \mathrm{~g}-\mathrm{h}$ and 5 ) and pelvis axial rotation (Figures $4 \mathrm{i}-\mathrm{j}$ and 5) were both very similar between the two golfers. Thus, it appears that it was the relatively small trunk axial rotation away from the target line that was the major contributor to the large difference between $2 \mathrm{D}$ and $3 \mathrm{D} \mathrm{X}$ factor for Golfer Three.

\section{Discussion}

This study compared trunk kinematics (flexion/extension, lateral bend, axial rotation) and X-factor during the golf swing using both $2 \mathrm{D}$ and $3 \mathrm{D}$ calculation methods of the same kinematic data in the general golfing population. Twodimensional trunk flexion was significantly greater (approximately $7^{\circ}$ ) than $3^{D}$ trunk flexion at top of the backswing and 2D trunk right-side lateral bend was significantly less than ${ }_{3} \mathrm{D}$ trunk right-side lateral bend at impact. The $2 \mathrm{D}$ trunk axial rotation away from the target was also greater (approximately $11^{\circ}$ ) than $3^{D}$ trunk axial rotation, although not statistically significant. These results support the first hypothesis that $2 \mathrm{D}$ trunk kinematic variables would be greater than $3 \mathrm{D}$ for 2 out of the 3 variables. The differences between $2 \mathrm{D}$ and ${ }_{3} \mathrm{D}$ trunk kinematic variables became more evident when examining individual golfers, especially for a single golfer who exhibited greater trunk right-side lateral bend. The degree of $3 \mathrm{D}$ trunk axial rotation, trunk right-side lateral bend, and pelvis axial rotation were significant explanatory variables for the differences between $2 \mathrm{D}$ and ${ }_{3} \mathrm{D} \mathrm{X}$-factor at top of the backswing. The result of the regression analysis supports the second hypothesis that trunk and pelvis orientations 
could explain differences between $2 \mathrm{D}$ and $3 \mathrm{D}$ X-factor, particularly at top of the backswing.

The shapes of the $2 \mathrm{D}$ and $3 \mathrm{D}$ trunk kinematics ensemble average curves were similar, but often varied in magnitude. Alkjaer et al ${ }^{17}$ identified increased magnitude of $2 \mathrm{D}$ joint moments compared with ${ }_{3} \mathrm{D}$ joint moments at specific events during gait. However, the patterns between data curves were very similar and, as a result, the authors concluded that $2 \mathrm{D}$ methods were appropriate to use for quantifying joint moments. A similar conclusion does not appear valid in this case for the golf swing as $2 \mathrm{D}$ and $3 \mathrm{D}$ calculation methods produced differences in trunk kinematic ensemble average curves which were shown to be significant at certain key swing instances such as top of the backswing and impact, although less so at takeaway. The increased differences at top of the backswing compared with takeaway could be due to the coupled movement of flexion/extension and lateral bend in the trunk that are not accounted for by $2 \mathrm{D}$ angles. Biomechanical coupling is a $3 \mathrm{D}$ concept where movement in a single direction, particularly for the trunk, can produce movement in other directions. ${ }^{18}$ It has been identified that $2 \mathrm{D}$ measurement methods used in studies exploring coupling movements leads to magnification of errors in the measurement of segment angles and subsequently misleading results. ${ }^{18}$ Interestingly, coupling patterns have been shown to vary between individuals, ${ }^{19}$ further strengthening the need for $3 \mathrm{D}$ analysis and offering an explanation for the varying level of agreement between $2 \mathrm{D}$ and 3D analysis of trunk kinematics for individual golfers found in this study (Figure 3). Similarly, the large range between the upper and lower LoA at all key swing instances (Table 2) suggests that these differences could be quite variable between golfers. Relationships to performance measures (clubhead velocity, ball velocity) have mostly been found for $2 \mathrm{D}$ measures of trunk flexion, trunk right-side lateral bend, and X-factor. ${ }^{5}$ Kwon et al, ${ }^{3}$ however, recently reported a lack of significant correlations between $3 \mathrm{D} \mathrm{X}$-factor and clubhead velocity at several stages in the swing, and warned that significant correlations between $2 \mathrm{D} \mathrm{X}$-factor and ball/clubhead velocity $^{5}$ should be interpreted with caution. Kwon et $\mathrm{al}^{3}$ suggested that fundamental differences in swing style (described as slope of swing plane, shape of clubhead trajectory) could influence both X-factor and clubhead velocity. These concerns are also relevant for previous significant relationships between $2 \mathrm{D}$

There were also evident differences in X-factor calculated using the $2 \mathrm{D}$ versus $3 \mathrm{D}$ methods for individual golfers (Figure 4). Overall, the group mean $2 \mathrm{D} X$-factor at top of the backswing showed increased rotation away from the target (by approximately $16^{\circ}$ ) compared with $3 \mathrm{D}$ X-factor. Kwon et $\mathrm{al}^{20}$ reported that, at top of the backswing, $2 \mathrm{D} \mathrm{X}$-factor was approximately $3^{\circ}$ greater than $3 \mathrm{D} \mathrm{X}$ - factor, which was consistent with the trend observed in this study. However, Brown et al2 reported $3 \mathrm{D} X$-factor to be greater than $2 \mathrm{D} \mathrm{X}$ factor at top of the backswing, by approximately $0.4^{\circ}$ (standard error $=0.2^{\circ}$ ). The relatively small differences between $2 \mathrm{D}$ and $3 \mathrm{D} \mathrm{X}$-factor found in previous studies, compared with this study, could be due to the homogenous groups of golfers that the previous studies have used. The subjects recruited for this study intentionally included a wide range of ages (1955) and handicaps (1-29) to obtain a wide range of trunk kinematics and $\mathrm{X}$-factor values so that potentially more noticeable effects could be seen between $2 \mathrm{D}$ and ${ }_{3} \mathrm{D}$ methods. This study was also able to show individual variations in the level of agreement between methods, which was a concerning factor for Brown et al. ${ }^{2}$ Brown et $\mathrm{al}^{2}$ noted that the difference between $2 \mathrm{D}$ and $3 \mathrm{D} \mathrm{X}$-factor varied between golfers and the mean difference did not reflect these individual golfer variations. Accurate estimation of X-factor at key instances, such as top of the backswing, is important in the analysis of the golf swing given that they have been shown to correlate with ball velocity ${ }^{5}$ and to have a suitable range of values for regression analysis. Parameters such as X-factor stretch rely on quantification of $\mathrm{X}$-factor at top of the backswing and maximum values and hence the methods used could affect the outcome. Furthermore, determining accurate timings of when maximum values occur during the swing may also be important to the performance outcomes of the swing (eg, ball distance and accuracy). For example, Tinmark et $\mathrm{al}^{21}$ found that the timing of pelvis, torso, and hand segment velocities showed a proximal-to-distal sequencing, which was suggested to affect shot accuracy. The differences between X-factor values obtained from $2 \mathrm{D}$ versus $3 \mathrm{D}$ methods at top of the backswing resulted primarily from the associated movements of lateral bend and axial rotation of the trunk and pelvis segments during the golf swing. Stepwise regression analysis suggested that both pelvis and trunk kinematic variables accounted for approximately $96 \%$ of the explained variance between $2 \mathrm{D}$ and ${ }_{3} \mathrm{D} \mathrm{X}$-factor calculation methods at top of the backswing (Table 3 ). The regression analysis suggested that golfers exhibiting lesser pelvis axial rotation away from the target would reduce the difference between $2 \mathrm{D}$ and $3 \mathrm{D} \mathrm{X}$-factor at top of the backswing. Conversely, golfers that had more trunk right-side lateral bend and lesser trunk axial rotation away from the target at top of the backswing would increase the difference between $2 \mathrm{D}$ and $3 \mathrm{D} \mathrm{X}$ factor at top of the backswing. This finding was supported by the example of the 2 golfers in Figure 4 and Figure 5. As mentioned previously, Kwon et $\mathrm{al}^{3}$ suggested that X-factor and clubhead velocity could be influenced by fundamental swing style differences which could have contributed to the significant correlations observed between $2 \mathrm{D} X$-factor and clubhead velocity in other studies. ${ }^{5,8}$ The results of this study have shown that the $\mathrm{X}$-factor measurement methods alone could be affected by changes in golfer's body movements in other planes (ie, trunk axial rotation and trunk right- side lateral bend) and therefore it is plausible that the $2 \mathrm{D} \mathrm{X}$-factor masks these additional golfer movements and the $2 \mathrm{D} \mathrm{X}$ factor would not be a suitable variable to correlate with measures of performance. Given the findings of this study and Kwon and colleagues'3 study that significant and technique-dependent differences between $2 \mathrm{D}$ and $3 \mathrm{D} \mathrm{X}$-factor occur during the golf swing, the results of previous studies reporting significant correlation between X-factor and ball velocity based on $2 \mathrm{D}$ measurement of the former should be treated with caution. The results of this study serve to promote a consistent approach for quantifying X-factor and trunk kinematic variables using 3D techniques which will ultimately help to understand whether there is a correlation between these variables and measures of performance such as ball velocity.

In conclusion, this study has calculated and compared trunk kinematics (flexion, lateral bend, rotation) and X-factor during the golf swing using both $2 \mathrm{D}$ and $3 \mathrm{D}$ analysis of the same kinematic data. The $2 \mathrm{D}$ methods led to significant differences in trunk extension at top of the backswing and trunk 
right-side lateral bend at impact. The degree of similarity between $2 \mathrm{D}$ and $3 \mathrm{D}$ trunk kinematics was highly dependent on the individual golfer's technique. The differences between $2 \mathrm{D}$ and $3 \mathrm{D} \mathrm{X}$-factor at top of the backswing were largely due to trunk extension, trunk axial rotation, pelvis axial rotation, and trunk right-side lateral bend. Once again, the degree of similarity between $2 \mathrm{D}$ and $3 \mathrm{D} \mathrm{X}$-factor were dependent on an individual golfer's technique. The primary source of differences appears to be associated with projecting vectors representing the trunk and pelvis onto a global plane throughout a 6 degree of freedom movement. Therefore, a golfer who has a greater degree of trunk flexion, trunk right-side lateral bend, or smaller degree of pelvis and trunk axial rotations may be susceptible to greater differences between $2 \mathrm{D}$ and ${ }_{3} \mathrm{D}$ methods. These results support the need to use $3 \mathrm{D}$ methods for analyzing a golfer's trunk or pelvis segment kinematics during the full golf swing. The results of this study also have implications for golf coaches, specifically in their use of $2 \mathrm{D}$ videography to assess a golfer's swing. Clearly, interpretation of these videos needs to be treated with caution, particularly with respect to assessing the rotational movements of the golfer's trunk and pelvis.

\section{References}

1. Joyce C, Burnett A, Ball K. Methodological considerations for the $3 \mathrm{D}$ measurement of the $\mathrm{X}$-factor and lower trunk movement in golf. Sports Biomech. 2010;9(3):206-221

doi:10.1080/14763141.2010.516446. PubMed

2. Brown SJ, Selbie WS, Wallace ES. The X-Factor: an evaluation of common methods used to analyse major inter-segment kinematics during the golf swing. J Sports Sci. 2013;31(11):1156-1163 doi:10.1080/o2640414.2013.775474. PubMed 3. Kwon Y-H, Han KH, Como C, Lee S, Singhal K. Validity of the $\mathrm{X}$-factor computation methods and relationship between the $\mathrm{X}$-factor parameters and clubhead velocity in skilled golfers. Sports Biomech, 2013;12(3):231-246.

4. Zheng N, Barrentine SW, Fleisig GS, Andrews JR. Swing kinematics for male and female pro golfers. Int J Sports Med.

2008;29(12):965-970 doi:10.1055/s-2008-1038732. PubMed 5. Chu Y, Sell T, Lephart S. The relationship between biomechanical variables and driving performance during the golf swing. J

Sports Sci. 2010;28(11):1251-1259

doi:10.108o/o2640414.2010.507249. PubMed

6. McTeigue M, Lamb SR, Mottram R, Pirozzolo F. Spine and hip motion analysis during the golf swing. Sci. Golf II Proc. World Sci. Congr. Golf 1994.

7. McLean J. Widen the gap. Golf Mag; 1992:49-53.

8. Myers J, Lephart S, Tsai Y-S, Sell T, Smoliga J, Jolly J. The role

of upper torso and pelvis rotation in driving performance during the golf swing. J Sports Sci. 2008;26(2):181-188

doi:10.1080/02640410701373543. PubMed

9. Cheetham PJ, Martin PE, Mottram RE, St. Laurent BF. The importance of stretching the "X-factor" in the downswing of golf: "the X-factor Stretch." In: Thomas PR, ed. Optimising Performance in Golf. Brisbane, Australia; 2001:192-199. http://www.philcheetham.com/wp- content/uploads/2011/11/Stretching-the-X-Factor-Paper.pdf 10. Zheng N, Barrentine SW, Fleisig GS, Andrews JR. Kinematic analysis of swing in pro and amateur golfers. Int J Sports Med. 2008;29(6):487-493 doi:10.1055/s-2007-989229. PubMed 11. Horan SA, Evans K, Morris N, Kavanagh J. Thorax and pelvis kinematics during the downswing of male and female skilled golfers. J Biomech. 2010;43(8):1456-1462

doi:10.1016/j.jbiomech.2010.02.005. PubMed
12. Coleman S, Anderson D. An examination of the planar nature of golf club motion in the swings of experienced players. J Sports Sci. 2007;25(7):739-748 doi:10.108o/02640410601113239. PubMed 13. Wheat JS, Vernon T, Milner CE. The measurement of upper body alignment during the golf drive. J Sports Sci. 2007;25(7):749-755 doi:10.108o/02640410601113213.

PubMed

14. Winter D. Biomechanics and Motor Control of Human Movement.

New York, NY: John Willey and Sons; 1990:11-50.

15. Richards J. The measurement of human motion: A comparsion of commercally available systems. Hum Mov Sci. 1999;18(5):589-602 doi:10.1016/So1679457(99)0o023-8.

16. Helwig NE, Hong S, Hsiao-Wecksler ET, Polk JD. Methods to temporally align gait cycle data. J Biomech. 2011;44(3):561566 doi:10.1016/j.jbiomech.2010.09.015. PubMed

17. Alkjaer T, Simonsen EB, Dyhre-Poulsen P. Comparison of inverse dynamics calculated by two- and three-dimensional models during walking. Gait Posture. 2001;13(2):73-77 http://www.ncbi.nlm.nih.gov/pubmed/11240354. PubMed doi:10.1016/Sog66-6362(oo)ooo99-o

18. Cook C, Showalter C. A survey on the importance of lumbar coupling biomechanics in physiotherapy practice. Man Ther. 2004;9(3):164-172 doi:10.1016/j.math.2004.03.003.

PubMed

19. Huijbregts P. Lumbar spine coupled motions : A literature review with clinical implications. Orthop. Div. Rev. 2004:21-25. http://www.shelbournephysio.ca/images/uploads/79/coupledmo tio ns.pdf

2o. Kwon Y-H, Como CS, Singhal K, Lee S, Han KH. Assessment of planarity of the golf swing based on the functional swing plane of the clubhead and motion planes of the body points. Sports Biomech. 2012;11(2):127-148. PubMed

doi:10.1080/14763141.2012.660799

21. Tinmark F, Hellström J, Halvorsen K, Thorstensson A. Elite golfers' kinematic sequence in full-swing and partial-swing shots. Sports Biomech. 2010;9(4):236-244

doi:10.108o/14763141.2010.535842. PubMed 